\begin{tabular}{cc} 
Araştırma Makalesi / Research Article & Harran Tarım ve Gıda \\
Gilimleri Dergisi (2016) & 20(4): 247-252 \\
Kabul tarihi: 12.07 .2016 & \\
\hline
\end{tabular}

\title{
Bazı Japon Grubu Erik (Prunus salicina Lindl.) Çeşitlerinin Gaziantep'teki Performansları
}

\author{
İzzet $\mathrm{AÇAR}^{1 *}$ \\ ${ }^{1}$ Harran Üniversitesi, Ziraat Fakültesi, Bahçe Bitkileri Bölümü, Şanlıurfa \\ *Sorumlu yazar: izzetacar@harran.edu.tr
}

Öz

Bu çalışma, 'Angeleno', 'Autumn Giant', 'Bella di Barbiano', 'Black Amber', 'Black Beauty', 'Black Diamond', 'Firenze 90', 'Fortune', 'Friar', 'Globe Sun', 'Larry Ann', 'Obilnaja', 'October Sun', 'Original Sun' 'President', 'Queen Rosa' ve 'TC Sun' Japon grubu erik (Prunus salicina Lindl.) çeşitlerinin Gaziantep'teki performanslarını belirlemek amacıyla yürütülmüştür. Çalışmada, ağaç başına verim, çiçeklenme dönemleri, hasat tarihi, meyve boyutları, meyve ağılığı, et/çekirdek oranı ve suda çözünebilir kuru madde içeriği (SÇKM) belirlenmiştir. Çalışmadan elde edilen sonuçlara göre; ağaç başına verim $0.5 \mathrm{~kg}$ (Firenze 90) ile $47.7 \mathrm{~kg}$ (Black Diamond) arasında değişirken, meyve ağırlı̆ı̆ $16.7 \mathrm{~g}$ (Obilnaja) ile $64.5 \mathrm{~g}$ (Larry Ann) arasında değişmiştir. Çalışmada kullanılan çeşitler arasında 'Larry Ann' ve 'Black Amber'in en iri meyvelere sahip olduğu belirlenmiştir. Çeşitlerin tam çiçeklenme tarihi 31 Mart (Queen Rosa) ile 12 Nisan (Firenze 90) arasında; hasat tarihi ise 11 Temmuz (Black Beauty ve Obilnaja) ile 13 Eylül (Angeleno ve President) arasında gerçekleşmiştir. Araştırmada kullanılan erik çeşitlerinin SÇKM oranı ise \%14.3 (Autumn Giant) ile \%22.5 (Angeleno) arasında değişmiştir. Bu çalışmadan elde edilen sonuçlara göre, 'Black Diamond', 'Globe Sun' ve 'Obilnaja' çeşitleri verim bakımından;'Black Amber' ve 'Larry Ann' meyve iriliği bakımından ve 'Black Beauty' ile 'Obilnaja' ise erkencilik bakımından öne çıkmışır.

Anahtar Kelimeler: Japon eriği, Prunus salicina Lindl., Çeşit performans

\section{Performances of some Japanese Plum (Prunus salicina Lindl.) Cultivars Grown in Gaziantep}

\begin{abstract}
This study was carried out in Gaziantep to determine the performances of 'Angeleno', 'Autumn Giant', 'Bella di Barbiano', 'Black Amber', 'Black Beauty', 'Black Diamond', 'Firenze 90', 'Fortune', 'Friar', 'Globe Sun', 'Larry Ann', 'Obilnaja', 'October Sun', 'Original Sun' 'President', 'Queen Rosa' and 'TC Sun' Japanese plum (Prunus salicina Lindl) cultivars. In the study, yield per tree, flowering periods, harvesting date, fruit dimensions, fruit weight, flesh/stone ratio and total soluble solid contents (TSS\%) were determined. According to obtained results; yield per tree $(\mathrm{kg})$ ranged from $0.5 \mathrm{~kg}$ (Firenze 90) to $47.7 \mathrm{~kg}$ (Black Diamond); fruit weight (g) ranged from16.7 g (Obilnaja) to $64.5 \mathrm{~g}$ (Larry Ann). Among the tested cultivars, 'Larry Ann' and 'Black Amber' had the biggest fruits. Full blooming date ranged from 31 March for 'Queen Rosa' to 12 April for 'Firenze 90', harvesting date ranged from 11 July for 'Black Beauty' and 'Obilnaja' to 13 September for 'Angeleno' and 'President'. TSS ratio of plum cultivars used in this study ranged between $14.3 \%$ for 'Autumn Giant' and 22.5\% for 'Angeleno'. According to the results, 'Black Diamond', 'Globe Sun' and 'Obilnaja' cultivars in terms of yield; 'Black Amber' and 'Larry Ann' cultivars in terms of fruit size; and 'Black Beauty' and 'Obilnaja' cultivars in terms of the earliness were found as promising.
\end{abstract}

Keywords: Japanese plum, Prunus salicina Lindl., Cultivar performance 


\section{Giriş}

Erik Rosales takımının, Rosaceae familyasının, Prunus cinsi ve Prunophora alt cinsi içine girmektedir. Ülkemiz bu türlerden, özellikle birçok önemli çeşidin doğduğu Prunus cerasifera Ehrh., $P$. insititia L. ve $P$. spinosa L.'nın gen merkezlerindendir. Ayrıca $P$. domestica L. ve $P$. salicina Lindl.'nın kültür formları da ülkemizde yetiştirilmektedir (Ayanoğlu ve Yılmaz, 1995; Özkarakaş ve ark., 2006).

Dünyada en fazla yetiştirilen erik türleri Prunus cerasifera, $P$. domestica, $P$. insititia ve $P$. salicina olup, Avrupa erikleri ( $P$. domestica) ve Japon erikleri ( $P$. salicina) ticari değerleri bakımından dünya erik yetiştiriciliğinde daha önemli bir yere sahiptir (Özbek, 1978). Japon grubu erikleri, ülkemizde Akdeniz Bölgesinde çok başarılı bir şekilde yetiştirilmektedir. 'Santa Rosa' ve 'Formosa' çeşitleri yıllardan beri bu bölgede yetiştirilen çeşitlerdir (Özgüven ve Küden, 1993). P. salicina Lindl. türünün anavatanı Çin'dir ve bu türe giren çeşitler Japon erikleri diye de adlandırılmaktadır. Önemli sofralık erik çeşitlerinin büyük bir çoğunluğu bu türden doğmuştur. Genellikle kışı soğuk geçmeyen Ilıman veya sıcak Ilıman bölgelerde iyi sonuç vermektedir. Son yıllarda yeni çeşitlerin de girmesiyle yurdumuzda üretimi hızla artmaktadır. Bu gruba giren erik çeşitleri Mayıs ortası ile Ekim ayları arasında olgunlaşmaktadır (Balık, 2005). Türkiye'de sofralık erik yetiştiriciliği daha çok Ege, Akdeniz ve Marmara bölgelerinde yoğunlaşmıştır. Özellikle erik bahçesi kurulurken Japon grubundan yüksek verimli erik çeşitlerinin tercih edilmesi sonucu üretim belirli miktarda artmıştır. Fakat dünyadaki gelişmeler yeterince takip edilememiş ve geliştirilen erkenci, kaliteli ve verimli erik çeşitlerinden yararlanılamamıştır.
$\mathrm{Bu}$ nedenle zaman içinde sofralık erik yetiştiriciliği ekonomik anlamda önemini yitirmiştir (Ayanoğlu ve Yılmaz, 1995). Erik ağaçları, özellikle $P$. cerasifera ve $P$. domestica türleri, ülkemizin hemen her bölgesinde yetiştirilmektedir. $P$. salicina türüne giren Japon eriklerinin yetiştiriciliği, son 20 yılda özellikle Akdeniz, Marmara, Ege ve geçit bölgelerinde artış göstermiştir (Son, 2010). Türkiye'nin hemen her yerinde yetişebilmesine rağmen, Akdeniz Bölgesi en büyük erik üretim bölgesidir. Bu bölgemizi Marmara ve Ege Bölgeleri izlemektedir. Bu bölgelerin üretimi, Türkiye erik üretiminin $3 / 4$ ünden daha fazladır (Bolat ve ark., 2015).

Güneydoğu Anadolu Projesi (GAP), ülkemizin en büyük sulama ve kalkınma projesi olup, yaklaşık 2 milyon hektar alanı kapsamaktadır. Türkiye'nin toplam erik üretiminin yaklaşık $\% 3^{\prime}$ lük bölümü Güneydoğu Anadolu Bölgesinde üretilmektedir. GAP projesiyle birlikte sulamanın başladığı bu bölgemizde, erik yetiştiriciliği bir artış eğilimine girmiştir (Bolat ve ark., 2015).

$\mathrm{Bu}$ çalışma, Japon grubu erik çeşitleri arasından, Güneydoğu Anadolu Bölgesi ekolojik koşullarına uygun olanları belirlemek amacıyla Gaziantep'te yürütülmüştür.

\section{Materyal ve Metot}

Bu araştırmada, 'Angeleno', 'Autumn Giant', 'Bella di Barbiano', 'Black Amber', 'Black Beauty', 'Black Diamond', 'Firenze 90', 'Fortune', 'Friar', 'Globe Sun', 'Larry Ann', 'Obilnaja', 'October Sun', 'Original Sun' 'President', 'Queen Rosa' ve 'TC Sun' Japon grubu erik çeşitleri kullanılmıştır. Çalışmada yer alan 17 erik çeşidi, her çeşitten 5 ağaç olacak şekilde Antepfıstığı Araştırma Enstitüsü Dr. Ahmet Münir BiLGEN Araştırma İstasyonunda $6 \times 5$ m dikim aralıklarında 2002 yılında dikilmiştir. Tüm çeşitler için 
Myrobolan 29 C klonal anacı kullanılmıştır. Sulama, damla sulama yöntemiyle ( 3 / $\mathrm{h}^{-1}$ damlatıcı debisi ve 8 saat süreyle sulama) Mayıs-Ekim ayları arasında haftada $2 \mathrm{kez}$ yapılmıştır.

Çalışmada, erik çeşitlerinin 2005 yılı araştırma sonuçları yer almakta olup, çeşitlerin ağaç başına verimlerinin yanı sıra fenolojik ve pomolojik özellikleri de belirlenmiştir.

\section{Fenolojik Gözlemler}

Çiçeklenme Dönemleri: Ağaçlardaki çiçeklerin \%5'inin açmış olduğu dönem ilk çiçeklenme, \%70'inin açtığı dönem tam çiçeklenme ve \%90'ının taç yapraklarını döktüğü dönem çiçeklenme sonu olarak değerlendirilmiştir.

Hasat Tarihi: Denemedeki çeşitlere ait meyvelerin olgunlaşma tarihleri, meyve tadı, meyve zemin ve et rengi ile meyvenin sertlik durumuna göre saptanmıştır.

\section{$\operatorname{Verim}(\mathrm{kg})$}

Ağaç başına verim değerleri 0.1 grama duyarlı dijital terazide tartılarak belirlenmiştir.

\section{Pomolojik Analizler}

Her çeşitten rastgele seçilen $25^{\prime}$ er adet meyvede pomolojik analizler yapılmıştır.

Meyve Eni $(\mathrm{mm})$ : Meyvelerin iki yanağı arasındaki mesafenin dijital kumpasla ölçülmesi sonucunda belirlenmiştir.

Meyve Boyu (mm): Meyvelerin karın çizgisi ile sırt çizgisi arasındaki mesafenin dijital kumpasla ölçülmesi sonucunda belirlenmiştir.

Meyve Yüksekliği (mm): Meyvelerin sap çukuru ile meyve ucu arasındaki mesafenin dijital kumpasla ölçülmesi sonucunda belirlenmiştir.
Meyve Ağırlığı (g): Meyvelerin 0.01 grama duyarlı dijital terazide tartılması sonucunda belirlenmiştir.

Et/Çekirdek Oranı: Meyve eti ağırlığının çekirdek ağırlığına bölünmesiyle elde edilmiştir.

Suda Çözünebilir Kuru Madde İçeriği (SÇKM) (\%): Meyvelerin SÇKM değerleri dijital refraktometre ile belirlenmiştir.

\section{istatistiksel Analizler}

Araştırma, tesadüf parselleri deneme desenine göre 5 tekerrürlü ve her tekerrürde 1 ağaç olacak şekilde kurulmuştur. Elde edilen verilerin varyans analizleri Minitab 11.12 (Minitab Inc.) istatistik programı kullanılarak yapılmış ve ortalamalar Duncan çoklu karşılaştırma testi ile \%5 önem seviyesinde karşılaştırılmıştır.

\section{Araştırma Bulguları ve Tartışma}

Araştırmada, ağaç başına verim, çiçeklenme dönemleri, hasat tarihi, meyve boyutları, meyve ağırlığı, et/çekirdek oranı ve suda çözünebilir kuru madde içeriği (SÇKM) belirlenmiştir.

Araştırmada kullanılan erik çeşitlerine ait fenolojik gözlemler Çizelge 1 'de verilmiştir. Çeşitlerin ilk çiçeklenme tarihleri 17 Mart (Queen Rosa) ile 5 Nisan (Firenze 90) arasında; tam çiçeklenme tarihleri 31 Mart (Queen Rosa) ile 12 Nisan (Firenze 90) arasında; çiçeklenme sonu tarihleri ise 3 Nisan (Queen Rosa) ile 15 Nisan (President) arasında değişmiştir.

Balık (2005), Kahramanmaraş'ta Japon grubu erik çeşitleriyle ilgili yürüttüğü çalışmada, ilk çiçeklenmeyi 1 Mart tarihinde 'Black Diamond', 'Fortune' ve 'Queen Rosa' çeşitlerinde saptadığını, bu çeşitleri 8 Mart tarihiyle 'Obilnaja'nın izlediğini ve en geç çiçeklenmenin ise 18 Mart tarihinde 'Autumn Giant' çeşidinde gözlendiğini bildirmiştir. 
Bostan (1997), Van ilinde yürüttüğü bir çalışmada, 'Black Beauty', 'Autumn Giant' ve 'President' çeşitlerinde sırasıyla tam çiçeklenme tarihlerinin 22-27 Nisan, 26-30 Nisan ve 24-27 Nisan olduğunu bildirmiştir. Çalışkan ve ark. (2006) ile Son (2010)'a göre en geç çiçeklenen çeşitler 'President', 'October Sun' ve 'TC Sun' olmuştur. Bizim çalışmamızdan elde ettiğimiz çiçeklenme tarihlerinin araştırıcıların sonuçlarından farklılık göstermesinin ekolojiden kaynaklandığı söylenebilir.

Çizelge 1. Erik çeşitlerinin fenolojik gözlem sonuçları

Table 1. The phenological observations of plum cultivars

\begin{tabular}{lcccc}
\hline $\begin{array}{l}\text { Çeşitler } \\
\text { Cultivars }\end{array}$ & $\begin{array}{c}\text { ilk Çiçeklenme } \\
\text { First Flowering }\end{array}$ & $\begin{array}{c}\text { Tam Çiçeklenme } \\
\text { Full Flowering }\end{array}$ & $\begin{array}{c}\text { Çiçeklenme Sonu } \\
\text { End of Flowering }\end{array}$ & $\begin{array}{c}\text { Hasat Tarihi } \\
\text { Harvesting Date }\end{array}$ \\
\hline Angeleno & 24 Mart & 4 Nisan & 8 Nisan & 13 Eylül \\
Autumn Giant & 27 Mart & 4 Nisan & 9 Nisan & 24 Ağustos \\
Bella di Barbiano & 20 Mart & 4 Nisan & 8 Nisan & 8 Ağustos \\
Black Amber & 26 Mart & 3 Nisan & 7 Nisan & 3 Ağustos \\
Black Beauty & 21 Mart & 2 Nisan & 5 Nisan & 11 Temmuz \\
Black Diamond & 24 Mart & 4 Nisan & 7 Nisan & 26 Temmuz \\
Firenze 90 & 05 Nisan & 12 Nisan & 14 Nisan & 26 Temmuz \\
Fortune & 20 Mart & 2 Nisan & 5 Nisan & 29 Temmuz \\
Friar & 23 Mart & 4 Nisan & 8 Nisan & 3 Ağustos \\
Globe Sun & 27 Mart & 8 Nisan & 13 Nisan & 19 Ağustos \\
Larry Ann & 20 Mart & 4 Nisan & 9 Nisan & 19 Ağustos \\
Obilnaja & 26 Mart & 5 Nisan & 8 Nisan & 11 Temmuz \\
October Sun & 27 Mart & 5 Nisan & 11 Nisan & 12 Ağustos \\
Original Sun & 27 Mart & 5 Nisan & 9 Nisan & 12 Ağustos \\
President & 04 Nisan & 11 Nisan & 15 Nisan & 13 Eylül \\
Queen Rosa & 17 Mart & 31 Mart & 3 Nisan & 26 Temmuz \\
TC Sun & 27 Mart & 8 Nisan & 11 Nisan & 24 Ağustos \\
\hline
\end{tabular}

Araştırmamızda kullanılan çeşitlerin meyvelerinin genel olarak Temmuz ve Ağustos aylarında olgunlaştığı, en erken olgunlaşmanın 11 Temmuz tarihinde 'Black Beauty' ve 'Obilnaja' çeşitlerinde olduğu, en geç olgunlaşmanın ise 13 Eylül tarihinde 'Angeleno' ve 'President' çeşitlerinde olduğu görülmüştür (Çizelge 1). Bilgü ve Seferoğlu (2005)'nun Aydın koşullarında yürüttükleri çalışmaya göre, 'Obilnaja' çeşidi en erken hasada gelen çeşit (23 Haziran) olmuş, 'Black Diamond' 5 Temmuzda, 'Queen Rosa' 12 Temmuzda, 'Fortune' 26 Temmuzda ve 'Autumn Giant' ise 13 Eylül'de hasada gelmiştir. Son (2010), Mut yöresinde Japon grubu erik çeşitlerinin olgunlaşma zamanının Haziran ortasından, Eylül ayının ilk haftasına kadar değiştiğini; 'Black Beauty' ve
'Oblinaja'nın 15-16 Haziran'da olgunlaştığını ve bu çeşitlerin diğer çeşitlerden bir ay erken olgunlaştığını; 'Autumn Giant', 'TC Sun' ve 'Angeleno' çeşitlerinin ise en geç olgunlaşan çeşitler olduğunu ve bunların Eylül ayının ilk haftasında olgunlaştığını bildirmektedir. Özakman ve ark. (1995), İzmir'de 34 Japon eriği çeşidi üzerinde yaptıkları çalışmada, çeşitlerin olgunlaşma tarihlerinin 7 Haziran ile 13 Eylül arasında değiştiğini bildirmektedir. Araştırmamızdan elde edilen bulgulara göre, Gaziantep ekolojisinde yetiştirilen erik çeşitlerinde Ege ve Akdeniz ekolojisine göre yaklaşık 15-20 günlük bir geççilik olduğu belirtilebilir.

Denemede kullanılan erik çeşitlerine ait ağaç başına verim değerleri ve pomolojik özellikler Çizelge 2 'de verilmiştir. Buna göre 
en yüksek verim $47.7 \mathrm{~kg}$ ağaç ${ }^{-1}$ ile 'Black Diamond' çeşidinden elde edilirken, en düşük verim 0.5 ve $1 \mathrm{~kg} \mathrm{ağaç}^{-1}$ ile 'Firenze 90' ve 'President' çeşitlerinden elde edilmiştir. 'Firenze 90' ve 'President' çeşitlerinde yeterli miktarda çiçek görülmüş, ancak bunların geç çiçek açması nedeniyle çiçeklenme dönemlerinde çevrede çiçekli başka ağaç kalmamasından dolayı, alınan önlemlere rağmen yoğun Bakla Zınnı zararı oluştuğu için bu çeşitlerde verim düşük olmuştur. Bilgü ve Seferoğlu (2005)'na göre, en yüksek verim 22 kg ağaç-1 ile 'Black Diamond' çeşidinden alınmış ve bunu sırasıyla $17 \mathrm{~kg}$ ağaç $^{-1}$ ile 'Obilnaja', 16 kg/ağaç ile 'Fortune', 13 kg ağaç-1 ile 'Queen Rosa' izlemiş, en düşük verim ise $0,9 \mathrm{~kg}$ ağaç-1 ile 'Autumn Giant' çeşidinden alınmıştır.

Meyvede en, boy ve yükseklik gibi boyut değerlerinin yanı sıra meyve ağırlığı ve SÇKM değerleri arasında istatistiksel olarak önemli farklılık olduğu belirlenmiştir (Çizelge 2). Boyut ve ağırlık bakımından en yüksek değerler 'Larry Ann' (64.5 g) ve 'Black Amber' (62.6 g) çeşitlerine ait meyvelerden elde edilirken, en düşük değerler 'Obilnaja' (16.7 g) çeşidinden elde edilmiştir. Araştırmada kullanılan çeşitlerin et/çekirdek oranları \%20.8 (Firenze 90) ile \%53.1 (Black Amber) arasında değişirken; SÇKM oranları \%14.3 (Autumn Giant) ile \%22.5 (Angeleno) arasında değişmiştir (Çizelge 2).

Çizelge 2. Erik çeşitlerinin verim ve bazı pomolojik özellikleri

Table 2. Yield and some pomological properties of plum cultivars

\begin{tabular}{|c|c|c|c|c|c|c|c|}
\hline $\begin{array}{l}\text { Çeşitler } \\
\text { Cultivars }\end{array}$ & $\begin{array}{l}\text { Ağaç başına } \\
\text { verim (kg) } \\
\text { Yield per } \\
\text { tree }(\mathrm{kg})\end{array}$ & $\begin{array}{l}\text { Meyve Eni } \\
\text { (mm) } \\
\text { Fruit width } \\
(\mathrm{mm})\end{array}$ & $\begin{array}{c}\text { Meyve } \\
\text { Boyu (mm) } \\
\text { Fruit } \\
\text { length } \\
\text { (mm) }\end{array}$ & $\begin{array}{c}\text { Meyve } \\
\text { Yüksekliği } \\
\text { (mm) } \\
\text { Fruit } \\
\text { height } \\
(\mathrm{mm}) \\
\end{array}$ & $\begin{array}{c}\text { Meyve } \\
\text { ağırlığı (g) } \\
\text { Fruit } \\
\text { weight }(g)\end{array}$ & $\begin{array}{c}\text { Et/Çekirdek } \\
\text { Oranı (\%) } \\
\text { Flesh/stone } \\
\text { (\%) }\end{array}$ & $\begin{array}{c}\text { SÇKM } \\
\text { (\%) } \\
\text { TSS } \\
(\%)\end{array}$ \\
\hline Angeleno & $16.9 \mathrm{bcd}$ & $42.1 \mathrm{e}$ & $42.1 \mathrm{de}$ & $37.5 \mathrm{hi}$ & 41.0 ef & 35.0 & $22.5 \mathrm{a}$ \\
\hline Autumn Giant & 14.5 cde & $45.1 \mathrm{bc}$ & $44.3 \mathrm{c}$ & $42.9 \mathrm{de}$ & $45.3 \mathrm{de}$ & 36.1 & $14.3 \mathrm{j}$ \\
\hline Bel. di Barbiano & $3.0 \mathrm{gh}$ & $42.3 \mathrm{e}$ & $41.9 \mathrm{e}$ & $38.8 \mathrm{gh}$ & $43.6 \mathrm{e}$ & 24.9 & $20.6 b$ \\
\hline Black Amber & $11.0 \mathrm{c}-\mathrm{f}$ & $50.0 \mathrm{a}$ & $46.9 a b$ & 43.4 de & $62.6 \mathrm{a}$ & 53.1 & $16.0 \mathrm{hi}$ \\
\hline Black Beauty & $5.7 \mathrm{fgh}$ & $45.8 \mathrm{~b}$ & $46.6 \mathrm{ab}$ & $42.3 \mathrm{e}$ & $54.3 \mathrm{bc}$ & 31.2 & $16.3 \mathrm{ghi}$ \\
\hline Black Diamond & $47.7 \mathrm{a}$ & 43.4 cde & $41.2 \mathrm{e}$ & $38.1 \mathrm{~h}$ & $37.5 \mathrm{fg}$ & 38.0 & $15.7 \mathrm{ij}$ \\
\hline Firenze 90 & $0.5 \mathrm{~h}$ & $45.1 \mathrm{bc}$ & 40.3 ef & $47.6 \mathrm{ab}$ & $52.4 \mathrm{bc}$ & 20.8 & $17.5 \mathrm{e}-\mathrm{h}$ \\
\hline Fortune & $9.3 \mathrm{~d}-\mathrm{g}$ & $45.0 \mathrm{bc}$ & $46.4 \mathrm{~b}$ & $45.8 \mathrm{bc}$ & $57.4 \mathrm{~b}$ & 37.9 & $19.4 \mathrm{bcd}$ \\
\hline Friar & $12.6 \mathrm{c}-\mathrm{f}$ & $40.0 \mathrm{f}$ & $38.9 \mathrm{f}$ & $39.4 \mathrm{gh}$ & $36.8 \mathrm{fg}$ & 26.2 & $17.3 \mathrm{e}-\mathrm{i}$ \\
\hline Globe Sun & $23.8 \mathrm{~b}$ & $36.8 \mathrm{~g}$ & $35.9 \mathrm{~g}$ & $40.3 \mathrm{fg}$ & $33.2 \mathrm{~g}$ & 27.5 & $16.9 \mathrm{f}-\mathrm{i}$ \\
\hline Larry Ann & 7.7 e-h & $49.0 \mathrm{a}$ & $48.3 \mathrm{a}$ & $44.7 \mathrm{~cd}$ & $64.5 \mathrm{a}$ & 35.5 & $18.9 \mathrm{cde}$ \\
\hline Obilnaja & $23.6 \mathrm{~b}$ & $30.1 \mathrm{~h}$ & $29.7 \mathrm{~h}$ & $28.6 \mathrm{j}$ & $16.7 \mathrm{~h}$ & 22.5 & $17.0 \mathrm{f}-\mathrm{i}$ \\
\hline October Sun & $5.1 \mathrm{fgh}$ & $44.2 \mathrm{bcd}$ & $41.8 \mathrm{e}$ & $46.0 \mathrm{bc}$ & $49.4 \mathrm{~cd}$ & 44.9 & $17.8 \mathrm{efg}$ \\
\hline Original Sun & $17.4 \mathrm{bc}$ & $42.4 \mathrm{e}$ & $39.0 \mathrm{f}$ & 42.0 ef & 40.7 ef & 39.0 & 18.0 def \\
\hline President & $1.0 \mathrm{~h}$ & $43.0 \mathrm{de}$ & $41.8 \mathrm{e}$ & $49.0 \mathrm{a}$ & $53.8 \mathrm{bc}$ & 23.5 & $20.1 b c$ \\
\hline Queen Rosa & $15.1 \mathrm{cde}$ & $45.9 \mathrm{~b}$ & $43.7 \mathrm{~cd}$ & $40.2 \mathrm{fg}$ & $51.0 \mathrm{c}$ & 27.1 & $16.1 \mathrm{hi}$ \\
\hline TC Sun & $18.3 \mathrm{bc}$ & $40.5 \mathrm{f}$ & $36.5 \mathrm{~g}$ & $35.9 \mathrm{i}$ & $33.8 \mathrm{~g}$ & 26.6 & $18.0 \mathrm{def}$ \\
\hline LSD \%5 & 7.05 & 1.57 & 1.66 & 1.81 & 4.71 & -- & 1.44 \\
\hline
\end{tabular}

Westwood (1978), suda çözünebilir kuru madde içeriğinin erikler için \%14-16 arasında olduğunu bildirmiştir. Son (2010)'a göre 'Black Diamond', 'Queen Rosa' ve 'October
Sun' çeşitlerinin meyve ağırlıkları, diğer çeşitlerden daha üstün bulunmuş; en yüksek et/çekirdek oranı değeri 'Black Amber' çeşidinden elde edilmiş ve bu çeşidi 'Autumn 
Giant' ve 'Black Diamond' izlemiştir. En düşük oran ise 'President' çeşidinden elde edilmiştir. Araştırmamızdan elde edilen bulgular Son (2010) ile uyumlu bulunmuştur.

\section{Sonuçlar}

Japon erikleri, kışı soğuk geçmeyen, ılıman veya sıcak ılıman bölgelere daha iyi uyum sağlamaktadır. Güneydoğu Anadolu Bölgesi ilkbahar geç donlarından daha az etkilenen bölgelerden biridir. Bu yönüyle Japon grubu erik çeşitlerinin üretiminde önemli olabilecek bir potansiyele sahiptir.

Çalışmanın yürütüldüğü Gaziantep ili, GAP Bölgesini temsil edebilecek ekolojik koşullara sahiptir.

Bu çalışmadan elde edilen sonuçlara göre, Japon grubu erik çeşitlerinden bazılarının gerek verim, gerekse meyve kalitesi bakımından GAP Bölgesine uygun olabileceği düşünülmektedir. Bu çalışmadan elde edilen 1 yıllık sonuçlara göre, meyve verimi bakımından 'Black Diamond', 'Globe Sun' ve 'Obilnaja' çeşitleri; meyve kalitesi bakımından 'Black Amber', 'Larry Ann' ve 'Black Diamond' çeşitleri; erkencilik bakımından ise 'Black Beauty' ve 'Obilnaja' çeşitleri GAP Bölgesi için uygun erik çeşitleri olarak değerlendirilebilir.

\section{Ekler}

$\mathrm{Bu}$ çalışma TAGEM tarafından desteklenmiş ve Antepfıstığı Araştırma Enstitüsünde yürütülmüştür. Araştırmada materyal olarak kullanılan fidanlar Dr. Yaşar ERBiL tarafından sağlanmıştır.

\section{Kaynaklar}

Ayanoğlu, H., Yılmaz, M., 1995. Doğu Akdeniz Bölgesinde Sofralık Erik Seleksiyonu Türkiye II. Ulusal Bahçe Bitkileri Kongresi Cilt I. (Meyve): 189-193.
Balık, S., 2005. Kahramanmaraş'ta dış Satıma Yönelik Japon Grubu (Prunus salicina Lindl.) Sofralık Yeni Erik Çeşitlerinin Yetiştiriciliği Üzerine Araştırmalar. Kahramanmaraş Sütçü İmam Üniversitesi, Fen Bilimleri Enstitüsü, Yüksek Lisans Tezi, $51 \mathrm{~s}$, Kahramanmaraş.

Bilgü, G., Seferoğlu, G., 2005. Japon Grubu (Prunus salicina L.) Bazı Erik Çeşitlerinin Aydın Yöresindeki Gelişme Durumlarının Belirlenmesi. ADÜ Ziraat Fakültesi Dergisi 2 (2) : 95-100.

Bolat, I., Ak, B.E., Acar, I., Ikinci, A., 2015. Plum Culture in Turkey. III. EUFRIN Plum and Prune Working Group Meeting on Present Constraints of Plum Growing in Europe. 20-21 August 2015, Skopelos, Greece (baskıda).

Bostan, S.Z., 1997. Van'da Yetiştirilen Bazı Erik Çeşitlerinde Önemli Fenolojik ve Pomolojik Özelliklerin Belirlenmesi. Ondokuz Mayıs Ünv. Ziraat Fakültesi Dergisi, 2(12): 3-6.

Çalışkan, T., Eken, M., Bircan, M., 2006. Studies on the Adaptation of New Japanese Plum Cultivars to the Different Regions of Turkey. Report of Horticulture Research Institute of Alata, Mersin, Turkey, p. 18.

Özakman, S., Önal, K., Özkarakaş, İ., Gönülşen, N., 1995. Ege Bölgesine Uygun Japon Erikleri (Prunus salicina Lindley)'nin Belirlenmesi Üzerine Araştırmalar. Türkiye II. Ulusal Bahçe Bitkileri Kongresi Cilt I. (Meyve): 194-198.

Özbek, S., 1978. Özel Meyvecilik. Ç.Ü. Zir. Fak. Yay. No. 128. Adana, $486 \mathrm{~s}$.

Özgüven, A.I., Küden, A., 1993. Investigations on some of the Plum Varieties in Çukurova Region (Turkey). V. International Symposium on Plum and Prune Genetic, Breeding and Pomology. Acta Hortic. 359: 118-122.

Özkarakaş, i.., Ercan, N., Gürnil, K., 2006. Ege Bölgesinden Toplanan Bazı Yeşil Erik (Prunus cerasifera Ehrh.) Materyalinin Değerlendirilmesi. Anadolu, Ege Tarımsal Araştırma Enstitüsü Dergisi, 16 (2): 35-49.

Son, L., 2010. Determination on Quality Characteristics of some Important Japanese Plum (Prunus salicina Lindl.) Cultivars Grown in Mersin-Turkey. African Journal of Agricultural Research. 5 (10): 1144-1146.

Westwood, M.N., 1978. Temparete Zone Pomology W. N. Freman and Company, Newyork, 428 p. 